\title{
Constructing responsibility in social interaction: an analysis of responsibility talk in hospital administrative groups
}

\author{
Eveliina Pennanen, Leena Mikkola \\ Department of Language and Communication Studies, University of Jyvaskyla, Finland
}

\begin{abstract}
The role of responsibility in hospitals is undeniable. Although administrative groups are essential to organizational performance, previous group and team studies of responsibility in hospital organizations have concentrated mainly on healthcare teams. This study aims to describe and understand responsibility construction in the social interaction in hospital administrative group meetings, based on observation and analysis of seven administrative group meetings in a Finnish hospital. Categories generated by thematic content analysis were compared with responsibility types. The findings show that responsibility is constructed by creating co-responsibility, taking individual responsibility, and constructing non-responsibility. Action and role and task responsibilities emerged as types from the interaction. To support employee involvement in responsibility processes, they must also be provided with sufficient resources to deal with that responsibility and to manage its different dimensions. These insights can be utilized to improve administrative groups.
\end{abstract}

\section{Introduction}

Responsibility is a feature of all kinds of social structure, from small social units to large societal contexts. ${ }^{1,2}$ Responsibility for work performance, objectives, tasks,

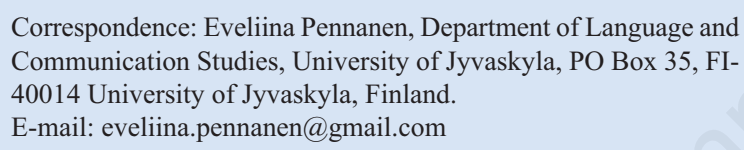

Key words: Administrative groups; Hospital; Responsibility; Social interaction; Workplace communication.

Contributions: the present article is part of the first author's doctoral dissertation that was prepared under the supervision of the second author.

Conflict of interest: the authors declare no potential conflict of interest.

Funding: the authors report grants from the University of Jyvaskyla, Faculty of Humanities, and from the Finnish Work Environment Fund (112304) during the conduct of the study.

Ethical statement: the study was approved by the Central Finland Hospital District. The ethical principles of the Finnish Advisory Board on Research Integrity (2015) were followed.

Received for publication: 2 October 2017.

Revision received: 27 August 2018.

Accepted for publication: 28 August 2018.

This work is licensed under a Creative Commons Attribution NonCommercial 4.0 License (CC BY-NC 4.0).

CCopyright E. Pennanen and L. Mikkola, 2018

Licensee PAGEPress, Italy

Qualitative Research in Medicine \& Healthcare 2018; 2:154-164

doi:10.4081/qrmh.2018.7114 and duties is also a crucial aspect of work and organizations. Yet although this relational concept is an established element of individuals, groups, or societies, ${ }^{1}$ little is known about how responsibility is constructed in social interaction. This study aims to describe and understand responsibility construction in social interaction in hospital administrative groups.

The performance of a hospital's various systems (such as administration) and interrelated units (such as departments) affect the performance of the organization as a whole. ${ }^{3}$ In the daily work of hospitals, responsibility is a significant construct, often connoting medical responsibility. In this regard, safe information sharing, multi-professional collaboration, and decision-making in relation to patient care all require careful consideration in terms of responsibility and its distribution. ${ }^{4-6}$ Yet, although administrative groups form an essential basis for organizational performance, earlier group and team studies in hospital organizations have tended to concentrate on healthcare teams. ${ }^{7,8}$ Responsibility constructed in social interaction in administrative contexts, for instance, balancing the different expectations of medical and administrative work, ${ }^{8,9}$ may make the responsibility in social interaction in administrative work a more complex phenomenon to deal with.

Administrative groups, like the many kinds of management groups and staff group meetings, can be described as resource groups, which perform administrative and expertise-based work. They thus often bear a lot of responsibility in organizations. Responsibility is not only a significant organizational aspect but also an important societal theme. Responsibility is a significant issue at both organizational and societal levels. In Finland, as in other Nordic countries, a wide-ranging state-funded public sector delivers services like education and healthcare. Consequently, administrative groups play a central role in society, as they are responsible 
for maintaining performance in these public organizations. This societal dimension also links administrative responsibility to institutional issues.

The theoretical perspective adopted here is informed by Lammers and Barbour's institutional theory of organizational communication. ${ }^{10}$ The concept of institution can be used to describe organizations, governing bodies, and some traditional professions (e.g., medicine), as well as practices, rules, behaviors, beliefs, or ways of thinking that can be characterized as continuing or fixed. As authority, status, or power is often emphasized, institutions extend beyond the particular organization; for example, the hospital institution includes not only the organization's various units and professions but certain fixed ways of behaving, thinking, acting, and approving or justifying behaviors and beliefs. ${ }^{10}$

Because institutions are created, reproduced, and sustained by social processes, communication plays a crucial role. ${ }^{10}$ In the present study, the hospital is approached as an institutional system, in which certain fixed practices and beliefs guide performance. ${ }^{10}$ The creation and distribution of responsibility can be understood as one aspect of these fixed practices, processes, and behaviors. For instance, professional roles entail certain traditional approaches to responsibility at work; doctors bear medical responsibility, and this affects how responsibility is perceived in other hospital work contexts, reflecting the institutional nature of hospitals.

The perspectives of the institutional theory emphasize the meaning of administrative groups, such as management groups and of staff group meetings, in organizations. Rather than performing manufacturing or operational processes, administrative groups produce various resources - for example, by coordinating, organizing, developing, innovating, and creating knowledge - and are commonly responsible for maintaining organizational processes. ${ }^{11}$ Administrative groups may be both strategic and executive. ${ }^{12,13}$ Because of their resource-related role, these groups are central to meaning in the processes and outcomes of organizations and their members..$^{14,15}$ Administrative groups are commonly responsible for certain organizationally defined matters, and the dimensions of that responsibility are constructed through social interaction within these groups - for instance, when coordinating work. ${ }^{11}$ Institutional organizing is adjusted through communication, and the institutional hierarchy is also established through these communicative organizing processes. ${ }^{10}$ It follows that social interaction in administrative groups reflects both the participants' qualities and the institution beyond the organization, which also affects group behavior. Social processes such as responsibility creation can therefore be seen to encompass both group and institutional levels. In hospitals, where responsibility and its distribution play a crucial role, it becomes important to understand the processes of responsibility construction in social interaction.

\section{Earlier research on responsibility}

Responsibility structures social reality, and as a social construction, it is also relational. For present purposes, we adopt Lenk's ${ }^{1}$ definition of responsibility as a relational construct - that is, responsibility arises when "someone is responsible to somebody for something in view of an addressee (object of responsibility) in relation to a normative criterion within a specific realm of responsibility and action" (p. 212). ${ }^{1}$ Additionally, many responsibilityrelated phenomena are interconnected (e.g., internal/external control and accepting/denying responsibility). ${ }^{2}$ Responsibility is also an attributional concept, where someone holds someone else accountable. ${ }^{16,17}$

In organizational studies, responsibility is often studied in terms of the social responsibility of a business or organization. ${ }^{18,19}$ Business ethics perspectives have also informed investigations of internal stakeholders (e.g., obligations between employees and employers) and external stakeholders (e.g., responsibility to customers) ${ }^{20}{ }^{\mathrm{How}}$ ever, this research has tended to focus on responsibility as something fixed or stable rather than as a dynamic process that is created, maintained, or changed in social interaction. In intraorganizational studies of teams and groups, responsibility means accepting or denying responsibility as part of the team's or group's activities - for example, being in charge of facilitating or improving the team's work..$^{21}$ The distribution of responsibility has also been studied in the context of responsibility rotation through collaboration among group members ${ }^{22}$ and of responsibility sharing, as in team empowerment and motivation arising from a sense of responsibility for or ownership of the work..$^{23}$ By focusing on group activities, such studies have enhanced our understanding of targeted and shared responsibility. However, there is little understanding of how responsibility is constructed among people inside organizations, or of the forms that such responsibility may take. That information would help to clarify the various aspects of responsibility and to support employees in dealing with it.

In healthcare contexts, the term responsibility often refers to medical or ethical accountability. It is important to properly understand who is in charge of what, as any lack of clarity about responsibilities threatens the safety of information-sharing processes. ${ }^{6}$ In particular, responsibility is central to handoff or handover situations - transitions in care during which patient information, authority, and responsibility are transferred between units, departments, employees, or shifts. ${ }^{6,24}$ Handoff communication affects patient safety ${ }^{24}$ and organizational ethics in executing other processes such as communication of critical information. ${ }^{5}$ Responsibility in healthcare contexts is also discussed in terms of shared decision making, as for instance when patients collaborate with healthcare professionals in making decisions about their care. ${ }^{25,26}$ These studies focus on specific situations and on the practices of healthcare teams. At the administrative level, there is 
evidence that engaging and empowering hospital staff members in organizational decision making can contribute to a positive patient safety climate and positive organizational citizenship. ${ }^{27}$ This finding suggests that responsibility talk in administrative groups can support important institutional tasks by grounding performance. However, this neglected relational perspective has not yet addressed the types of responsibility discussed and constructed in administrative arenas.

The present study broadens this area of research by exploring how responsibility is constructed in administrative groups and the types of responsibility constructed. Lenk $^{1}$ identified three types of responsibility: action, role and task, and universal moral responsibility. Action responsibility refers to accountability for the outcomes and consequences of a given action. Role and task responsibility relates to fulfilling the duties and expectations associated with a specific role or task at work or elsewhere. ${ }^{1}$ Role duties may be assigned or informal; in organizations, they may be linked to institutional role responsibilities such as leadership. ${ }^{1}$ Universal moral responsibility may be either direct or indirect. ${ }^{1}$ Direct moral responsibility relates to someone's actions and their consequences in a specific context; ${ }^{1}$ indirect responsibility arises at a more collective level and encompasses the actions of others, linking to group responsibility or co-responsibility. ${ }^{1}$ The present study applies Lenk's ${ }^{1}$ categories of action, role and task, and universal moral responsibility to the hospital context, which as an institution includes various levels of distinct and relatively fixed roles and tasks, and raises many moral and ethical questions.

\section{Aim of the study}

The study seeks to describe and clarify responsibility construction as a communicative phenomenon in hospital administrative group meetings by addressing the following research questions.

i) How is responsibility constructed through social interaction in hospital administrative group meetings?

ii) What types of responsibility (action, role and task, universal moral responsibility) emerge from social interaction in hospital administrative group meetings?

For present purposes, responsibility is seen to be created through social interaction, which is understood as a complex, situated, and mutual process, in which two or more people exchange messages to create shared meanings and accomplish social goals (p. 151). ${ }^{28}$ In healthcare organizations, social interaction is essential to creating and maintaining relationships, processing information, and creating an organizational culture. ${ }^{3}$ Moreover, many of the activities that form part of organizational life emerge from social interaction and the relationships created through the processes of communication. ${ }^{29}$ To add to knowledge in this regard, the present study approaches responsibility as a neutral phenomenon rather than characterizing it as positive or negative.

\section{Materials and Methods}

\section{Data collection}

Based on a qualitative design, observation and videoand audio-recording were used to collect data at seven administrative group meetings of one operational unit in a large Finnish public hospital. This formed part of a larger research project exploring social interaction practices in hospital organizations (Social Interaction Practices and Well-Being at Hospital Workplace, TSR112304). The unit was selected on the basis of a stated willingness to participate. All events occurred naturally and existed independently in the hospital workplace without the researchers' intervention; ${ }^{30}$ this qualitative method of naturalistic observation obtains data as unobtrusively as possible. ${ }^{31}$

The data were collected between August 2012 and May 2013. The researcher who gathered the data attended the meetings but did not participate in the discussions. Data were gathered from five management group meetings of the operational unit and from two employee cooperation meetings. The management group comprised 10 members, but only 6-8 attended each meeting. These meetings were chaired by the director in charge of the unit, who was also its chief physician. The other members included the department's senior physician, head nurses and their deputies, four members of the nursing staff, and a secretary who recorded the minutes of the meeting. The agenda addressed administrative matters such as resourcing and facilitation of the unit's work; its basic structure of the agenda was always the same and included finances, vacancies, and topical issues related to the unit. These meetings were held monthly, each lasting 45-70 minutes. Data were recorded using a $360^{\circ}$ panoramic camera; in total, $4 \mathrm{~h} 35 \mathrm{~m}$ of data were recorded.

In Finland, act-on cooperation in undertakings forms part of labor legislation. The law includes a negotiation obligation, which means that cooperation should be negotiated in undertakings involving 20 employees or more and where certain changes are planned. ${ }^{32}$ Although such negotiations are often interpreted as terminations, targets do not always include staff reductions but commonly address collective development of the organization's operations and employee involvement in decisions related to their work. ${ }^{32}$ Both employer and employees (or their representatives) should be present at such negotiations. ${ }^{32}$ In the unit observed for the purposes of this study, cooperation negotiations were organized in relation to changes concerning services, work methods, and work hours, among other issues.

The employee cooperation meetings from which data were collected were the only ones organized by the unit during the nine-month period of data collection. The 20 attendees at each meeting included employees (registered nurses, practical nurses, office secretaries, a departmental secretary, and employees who assisted in nursing work), managers (the chief physician, the head nurse, and the head 
nurse's deputies), employee representatives, and a labor union representative. The meetings were audio-recorded, as panorama video recording was not possible because of the meeting room facilities and the large number of participants. The first employee cooperation meeting lasted 1 hour and 3 minutes, and the second lasted 35 minutes. Total recorded data from the management group and employee cooperation meetings amounted to $6 \mathrm{~h} 13 \mathrm{~m}$.

The study followed the national guidelines for research ethics: respecting participant autonomy, avoiding harm, and protecting privacy and data. ${ }^{33}$ In Finland, an ethical review is not usually needed when the research participants are adults who volunteer to participate and when the study does not expose them to exceptionally strong stimuli or possible harm. On that basis, no IRP approval was sought.

\section{Analysis}

The analysis was performed in two phases. To answer the first research question, the aim was to determine how responsibility is constructed through social interaction in administrative group meetings. To answer the second research question, the aim was to identify which of Lenk's types (action, role and task, or universal moral responsibility) would emerge from these interactions. ${ }^{1}$

Thematic content analysis was used in both phases of analysis. ${ }^{34,35}$ After identifying, coding, and categorizing any patterns in the data, ${ }^{35}$ the aim was to identify the types of responsibility ${ }^{1}$ these processes created. The analysis focused on patterns in the data that could be recognized and interpreted, ${ }^{34}$ based on what happened in the interactions between attendees at each meeting, concentrating on themes that could be identified at the explicit, semantic level (what was said) and those occurring at the latent, interpretive level (what happened in the dynamics of the interaction). ${ }^{34,36}$ The unit of analysis was thus either a meaning unit that consisted of expressions or statements that were part of the same main meaning ${ }^{36}$ or an episode of the interaction that comprised more than one participation. ${ }^{37}$ While the analysis focused primarily on verbal communication, interpretations also took account of nonverbal communication, as this forms part of the totality in which shared meanings are created. ${ }^{38}$

The recorded meetings were first transcribed, read, and watched or listened to in their entirety. The data were coded by making notes to become familiarized; the initial list of codes gathered ideas from the data that were of immediate interest within the study framework and objectives. ${ }^{34,35}$ The dynamics of interaction were highlighted during this phase, and episodes in which responsibility was taken, shared, denied, avoided, or otherwise negotiated were identified and selected for analysis. After the coding phase, the data were categorized on the basis of shared meaning. The aim was to interpret the dynamics of the interaction - in other words, to analyze what happened when responsibility-related themes arose in the meetings. The categories were labeled as sharing responsibility, taking responsibility, and removing responsibility. The categories were then reviewed and refined, and the essence of the interaction was identified. ${ }^{34}$ At this phase, the coded data extracts were read through and considered whether these were coherent in relation to the data set, to one another, and to the research objectives. This led to the creation of subcategories and renaming of the main categories to more accurately capture their meaning as creating co-responsibility, taking individual responsibility, and constructing non-responsibility.

Following the inductive analysis, the second phase focused on identifying the different types of responsibility emerging from social interaction in the meetings, based on Lenk's ${ }^{1}$ categories (action, role and task, and universal moral responsibility) and referring to the explicit level of interaction. Action responsibility included matters related to actions, behaviors, or their consequences. ${ }^{1}$ Role and task responsibility related to role fulfillment or tasks and duties. ${ }^{1}$ Universal moral responsibility included the effects of the agent's activity on the well-being of others. ${ }^{1}$ These different forms of responsibility were identified in relation to the categories from the first phase of analysis, using qualitative content analysis to identify the interaction processes through which each was constructed. The trustworthiness of this analysis was strengthened by discussing methods and interpretations with colleagues in the research group.

The results are presented thematically, based on the main categories; both research questions are addressed in parallel as they form a coherent ensemble. The data examples presented in this article were translated by the authors from Finnish into English. The transcripts were anonymized to ensure that participants and departments could not be identified. In the examples, names of the units and treatments are replaced by xxx.

\section{Results}

The meeting participants constructed responsibility by creating co-responsibility, taking individual responsibility, and constructing non-responsibility. Table 1 presents the findings in relation to responsibility construction and the responsibility types that emerged from social interaction during administrative meetings.

\section{Creating co-responsibility}

The process of creating co-responsibility entailed sharing of responsibility between two or more persons or was warranted by institutional factors such as organizational policies. Attendees created co-responsibility through interaction by i) engaging someone else in the responsibility or ii) committing themselves to the responsibility. In this way, responsibility was not solely in the hands of the participant advancing the viewpoint or idea but was shared with someone or something else. 
The process of co-responsibility creation occurred within the dynamics of interaction. At the content level, participants often explicitly stated that someone or something would participate in sharing the responsibility with them, and other participants responded by accepting this. Construction of co-responsibility did not include rejection of shared responsibility, and attendees showed acceptance by acknowledging the matter addressed and moving on to the next topic, or by stating that the matter was acceptable to them.

Participants engaged another party in a responsibility by positioning someone or something else as co-responsible with them, stating that someone or something else supported the matter that they presented or that someone or something would join them in taking care of the matter.

In expressing that someone or something else supported the presented matter, participants referred to an individual or entity that agreed and so shared the responsibility. Participants often alluded to a higher level in the organizational hierarchy (occupied by a person or group) or to institutional features such as hospital policies or collective labor agreements that shared their viewpoint. In data example 1, the deputy engages both someone and something else in co-responsibility by referring to another manager and a collective labor agreement supporting the presented perspective.

\section{Data example 1}

Deputy (D) 1: So, I asked [how] the head nurses of department $000[\ldots]$ dealt with this issue. I mean, they face this same issue in their department; [...] their employees need to work in various places,- - So, she said they had long negotiations about this with employee representatives $[\ldots]$ for $[\ldots]$ months, and $[\ldots]$ concluded that you could not include travel time in your work hours. - It would then be defined like this. Or [...] according to the [collective] labor agreement, it would unfortunately go like this.

In referring to other head nurses and their information and to a collective labor agreement, D1 demonstrates that someone or something else shares responsibility. In this way, D1 creates co-responsibility.

In the process of expressing that someone or something else would take care of the matter together with the participant presenting it, another party is taken to co-share the responsibility for an action or activities. By mentioning shared responsibility, the participants made the issues' progress visible to one another. In data example 2, the chief physician positions the secretary as co-responsible for checking the schedules.

\section{Data example 2}

Chief physician (CP): Anyway, a cooperation meeting will be organized here in our office. It will now take place in April, but we will then check the exact date with Anne.

When the CP says "we will check the exact date with Anne," Anne is positioned as co-responsible for ensuring the right schedules; in other words, the $\mathrm{CP}$ does not bear this responsibility alone.

Table 1. Responsibility construction processes and types of responsibility.

\begin{tabular}{llll}
\hline $\begin{array}{l}\text { Responsibility } \\
\text { construction }\end{array}$ & Positioning & Social interaction process & Message content \\
\hline $\begin{array}{l}\text { Creating } \\
\text { co-responsibility }\end{array}$ & $\begin{array}{l}\text { Positioning someone or } \\
\text { something else as } \\
\text { co-responsible with } \\
\text { the participants }\end{array}$ & $\begin{array}{l}\text { Engaging someone else } \\
\text { in responsibility }\end{array}$ & $\begin{array}{l}\text { Someone/something else } \\
\text { supports the matter }\end{array}$ \\
& & & Task and role \\
\cline { 2 - 3 } & & &
\end{tabular}

\begin{tabular}{|c|c|c|c|c|}
\hline & & & & \\
\hline & & & $\begin{array}{l}\text { Someone/something will take } \\
\text { care of the matter together } \\
\text { with the participant }\end{array}$ & Action \\
\hline & $\begin{array}{l}\text { Positioning oneself as } \\
\text { co-responsible with } \\
\text { someone else }\end{array}$ & $\begin{array}{l}\text { Committing oneself to } \\
\text { responsibility }\end{array}$ & $\begin{array}{l}\text { Taking care of the matter } \\
\text { together with someone else }\end{array}$ & Action \\
\hline $\begin{array}{l}\text { Taking individual } \\
\text { responsibility }\end{array}$ & Responsibility bearer & Confirming responsibility & $\begin{array}{l}\text { Taking care of something } \\
\text { that will happen }\end{array}$ & Action \\
\hline & & & $\begin{array}{l}\text { Bearing responsibility for } \\
\text { something that happened } \\
\text { earlier }\end{array}$ & Action \\
\hline $\begin{array}{l}\text { Constructing } \\
\text { non-responsibility }\end{array}$ & Messenger & $\begin{array}{l}\text { Distancing oneself from } \\
\text { responsibility }\end{array}$ & $\begin{array}{l}\text { Unwillingness to take } \\
\text { responsibility and shifting } \\
\text { it to someone or something } \\
\text { else }\end{array}$ & Task and role \\
\hline & $\begin{array}{l}\text { Incompetent/unsure } \\
\text { of one's position }\end{array}$ & Refusing responsibility & $\begin{array}{l}\text { Giving reasons for not taking } \\
\text { responsibility }\end{array}$ & Task and role \\
\hline
\end{tabular}


Committing oneself to the responsibility was another way of constructing co-responsibility. The participants showed that they could or would share the responsibility by expressing that they would take care of the matter together with the attendee who spoke of it or with someone else who was not present at the meeting.

\section{Types of responsibility}

Creating co-responsibility entailed dimensions linked to activities, tasks, and roles. Stating that someone or something else supported the matter related to task and role responsibility, as this reasoning was based on the status of the person or group. This is demonstrated in data example 1, where D1's reasoning is based on status. D1 refers to other head nurses (having the status of leader) and to a collective labor agreement (having the status of a formal rule or law). Stating that someone would take care of the matter along with the participant was a form of action responsibility, as the process focused on activities. In data example 2, CP refers to another person (Anne) who will be responsible for the action along with $\mathrm{CP}$.

In these responsibility types, information played a significant role as a dimension of action responsibility. In a hospital context, information can be seen to establish, verify, and justify an action, where expertise forms the basis for operations and their quality. Mentioning that someone or something else supports the presented matter is a form of role and task responsibility. The reasoning was based on role duties or fulfillment of a certain role or task, as well as institutional role responsibilities, as the attendees referred to representative roles such as that of manager. Committing oneself to responsibility is a form of action responsibility, as it focuses on future activities and taking care of them.

Attendee status and the topic under discussion seem to define participation in the interaction processes associated with constructing co-responsibility. Someone with expertise on the discussed matter or credentials to influence others, such as a manager or a member of a certain project group, was engaged in the responsibility. An expert on the matter under discussion committed themselves to its related themes, and the discussion topic specified the creation of co-responsibility. When discussing challenging situations (e.g., some drawbacks at work), attendees indicated that their viewpoint was shared and supported by someone or something else (data example 1).

\section{Taking individual responsibility}

In taking individual responsibility, participants themselves assumed responsibility for a certain action or item of information, and responsibility was created in the communicative processes of confirming. In their interaction, participants explicitly stated that they were in charge of something. Individual responsibility was also negotiated with other attendees in situations where the others argued and showed support for the person who was trying to take individual responsibility.

By positioning themselves as responsibility bearers, participants confirmed through their interaction that the responsibility was theirs by expressing that one would take care of something that would happen or that one would take responsibility for something that happened earlier. In data example 3, a nurse confirms that responsibility for their lapse of memory is their own.

\section{Data example 3}

Nurse (N) 9: Oh, guess what? I forgot to figure that thing out. Well, I will ask and let you know next time how it is supposed to be done.

By indicating to others that they would take care of the matter, the individual's responsibility was also made visible to them. The procedure for writing the meeting minutes supported this kind of individual responsibility creation; although the secretary wrote the minutes throughout the meeting, it was highlighted that key issues needed to be carefully noted, and the responsibilities were often associated with those. Data example 4 illustrates this kind of interaction.

\section{Data example 4}

D2: Well, let's write it down carefully now so that it will be taken into account.

By expressing the importance of writing down a significant theme, D2 takes responsibility. Taking notes also made responsibilities visible at unit or organizational level, and minutes were shared with other work groups and staff members. The responsibility was confirmed mainly by the head nurse and chief physician, who also had the formal power to proceed with the activities in their unit.

Taking responsibility for something that happened earlier was also covered by expressing that one would take responsibility for one's actions. This occurred when participants recognized and explained their own errors - for instance, not doing something that they were supposed to do. In these cases, accountability for a mistake was not shifted to something or someone else but was presented as one's own fault. This kind of responsibility-taking won support from other participants, who responded with acceptance. They showed support by justifying the error in terms of external factors, and the nature of the work (e.g., too much administrative work, complex hospital policies) was used to explain someone's memory lapse. By showing acceptance, the others justified the individual's mistake and diffused individual responsibility.

\section{Types of responsibility}

Action responsibility became visible in confirming that one took responsibility for one's actions, and future and past dimensions of responsibility emerged. Stating that one would take care of something was linked to the 
future, where a participant said that they would progress a task or duty outside the meeting. This is the case in data example 3, where the participant says that they will take care of something outside the meeting and will inform others about it at the next meeting. The past dimension emerges in the process of taking responsibility for one's actions, as the action or its consequences are explained. However, task and role responsibility were also seen to emerge from these processes if the actor positioned as responsibility bearer was considered. In many cases, the head nurse or chief physician accounted for their past actions or the consequences, and others justified it, so diffusing individual responsibility.

\section{Constructing non-responsibility}

Participants constructed non-responsibility by shifting responsibility from themselves (or from their own unit or group) to someone or something else. The process occurred in the dynamics of the interaction, which included a mutual negotiation of giving or offering responsibility but not taking it. Responsibility was removed by i) distancing themselves and ii) refusing responsibility. These processes created the dimensions of willingness and the opportunity to influence work-related matters and take responsibility at work.

Participants distanced themselves from responsibility by positioning themselves as messengers delivering someone else's message. This unwillingness to take responsibility emerged when someone stated that the shared information or viewpoint was not their own but came from someone or something else. Often, the position of messenger was highlighted by reading a message, such as the minutes of another meeting. In this way, the participant distanced themselves from the responsibility, shifting it to the message sender or to an institutional body (such as another management group), whose information the participant was only reporting. In data example 5 , a nurse distances herself from responsibility by bringing up a topic originally suggested by another nurse. At the end, however, she mentions that all of the other nurses also support the matter.

\section{Data example 5}

N10: Well, I am saying this on behalf of Matt Mattson. This thing about these deputyships is that they are conducted in health centers. I will now read this in its entirety, so that it will be presented correctly as he has phrased it. So [starts to read]: "Because of the expansion of the performance of the hospital, we face a new kind of situation. The deputyships are filled on a voluntary basis." [...] [reads the whole message explaining the flaws of the new situation in detail and then continues]. All in all, so that these deputyships can be covered without any difficulty, Matt suggests that the travel time to other towns for these nursing deputy assignments should be included in work time, and that volunteers who are willing to travel to health centers would be asked [to take] these assignments in the first place. He thinks that it would be good to have 10 to 15 nurses ready to take these deputy positions to ensure that we can also cover our vacation periods. Matt then adds: [reads] "For myself, I think the option of working in health centers too enriches my job, and I will also be happy to take these assignments in the future. I hope the issues I've raised will be considered" [stops reading]. As all of us xxx nurses broadly share these thoughts, it would be really good if travel time could be included in our work hours, as travelling extends the length of the working day by several hours.

In that example, the nurse claims to be reporting something on behalf of someone else, so distancing themselves from responsibility. Eventually, the responsibility acquires a collective dimension, as the nurse says that "all of us xxx nurses broadly share these thoughts."

Rejecting/refusing to take responsibility occurred in an interaction in which responsibility was offered to someone who declined it, or where it was expected to be accepted but a reason was given for not doing so. Participants did this by expressing hesitancy about their position.

Participants positioned themselves as incompetent by explaining that they had insufficient information to take responsibility - for instance, to make a decision. They reasoned that, because of their position in the organization, they lacked the necessary information, either because someone else was in charge of the task or because they did not receive the information from someone although they had requested it. In these interactions, participants refused responsibility by stating that they could not determine the right decision or how to perform the task or duty in question. They also rationalized their refusal by referring to insufficient opportunities to take responsibility or to their lack of credentials. In this way, the participants positioned themselves as unsure of their position. These processes also related to diffusing responsibility - for instance, the chief physician might first try to transfer the responsibility to a nurse, who would refuse and try to hand it back.

In data example 6 , the chief physician offers responsibility to the nurses by saying that they can decide for themselves how to handle a case involving new treatment practices. However, one nurse refuses the responsibility and tries to involve someone else in deciding or confirming what to do.

\section{Data example 6}

CP: So, they will need some patients for these training sessions. Patients, xxx patients. Because they have different kinds of equipment there, and they [nods toward N1] and you [nods toward N3] don't know how to use them. N3: Well, yeah.

[...]

N3: What kinds of treatment, and how many of them, are needed? 
CP: Just whatever you have. I guess you just need to go through the appointment lists and pluck the xxx patients from there; this can be done over there, and then ask the staff who are there in these training sessions.

N3: Umm.

CP: How about our nurses - is it possible for them to participate?

N3: Yes, it is.

$[\ldots]$

CP: Yes, so patients are needed then, over there.

N3: How many patients?

PJ: You know better yourselves.

N3: It is $[\ldots]$

N1: It will be like [...]

CP: So many patients that it won't mean rushing around, but it should be possible to really concentrate on them [N3: I wish I knew...]. I think the trainer can tell you.

N3: Mmm.

This data example illustrates responsibility rejection; the CP offers it, but the nurses do not take it. Instead, they say they are unsure, and they try to get someone else to decide the right number of patients. In the end, the $\mathrm{CP}$ takes the responsibility by deciding that the trainer can tell them. In this way, the $\mathrm{CP}$ also diffuses responsibility by deciding that someone else can decide and provide the nurses with the right information.

\section{Types of responsibility}

Task and role responsibility emerged in refusing responsibility by distancing oneself from it. Responsibility was shifted to someone or something else, referring to a role or task that explained the content of the message. In this way, responsibility was perceived to fall elsewhere and not to the individual reporting the matter.

Responsibility was often removed at institutional or organizational level, where a manager could shift it to higher management ("they decide") or to the employees ("you know better how it should be done in practice"). Equally, employees could transfer it to managers ("We are not sure how this should be done"). The nature of nursing work or managers' work, organizational structures, the hospital culture, or a lack of certainty about future changes were used to position oneself as someone who could not or would not take responsibility, or was otherwise unsure about how to decide, act, or perform. Responsibility was also diffused at a more abstract level, as it was not always specified or negotiated to whom the responsibility was shifted.

To conclude, administrative work encompasses many elements of responsibility. Responsibility was constructed by creating co-responsibility, taking individual responsibility, or constructing non-responsibility. While action responsibility and role and task responsibility emerged from these interactions, the data did not include universal moral responsibility. These findings are discussed in the next section.

\section{Discussion}

Our results suggest that collective responsibility is emphasized in hospital administrative groups. Even individual responsibility construction was linked to collective responsibility, as it involved institutional memberships and referrals; in this way, responsibility construction became collective. ${ }^{1}$ This might be explained in terms of institutional role responsibilities, as responsibility often seemed representational, as in fulfilling the role of leader and its associated obligations, expectations, and responsibilities. ${ }^{1}$ Collective responsibility was also created by diffusing responsibility, where others justified an individual's actions or their consequences. This indicates responsibility management, where people attempt to regulate their feelings of guilt by rationalizing the action and its consequences, so putting attributions of responsibility into perspective. It is important to note that these justifications do not always deny accountability but offer reasons for reducing or removing blame and liability. ${ }^{39}$ This kind of responsibility diffusion can also be interpreted as a form of social support that helps employees to manage anxiety and stress at work. ${ }^{29}$

The findings also revealed instances of non-responsibility, constructed by distancing oneself and refusing to take responsibility. For example, positioning oneself as a messenger may be a strategy for saving oneself by declining responsibility for some controversial matter. Mon$\operatorname{tada}^{39}$ noted that, by using this kind of strategy, one can protect oneself against blame, sanctions, and feelings of guilt and self-blame. However, our findings also suggest that responsibility may be rejected on grounds of a lack of ability or resources, which may also account for the findings regarding responsibility denial. For instance, nurses may refuse to take responsibility because they lack the necessary resources to deal with it, as their everyday work with patients is often based on someone else's requests and decisions. In this way, institutional roles may also determine involvement in an administrative context.

The present findings also illuminate the interesting role of temporality, as responsibility was created in both past and future dimensions. The results support Birnbacher's ${ }^{17}$ view that responsibility can relate to past activities or their consequences or to producing certain conditions of a specific matter. These processes can produce the shared reality of an organization's past and future. Interactions that reflect the past and anticipate the future can also contribute to the fixed nature of institutions that maintain their structure by creating accepted understandings of the work and the workplace. This also links to the relational level of the workplace; as well as providing the context in which social interactions occur, relationships also entail patterns, boundaries, and institutions that are created and evolve through dynamic interaction. ${ }^{29}$ As compared with roles, which are often perceived as relatively static, positions are ephemeral as collections of be- 
liefs that relate to group members' rights and duties and to expectations to act and behave in a particular way. ${ }^{40-43}$ It follows that an individual's role can encompass many positions, as this study's findings also indicate. The data suggest that hesitancy about one's own position emerges from the process of refusing responsibility. Simultaneous membership of administrative and other kinds of group (e.g., healthcare teams) creates multiple roles and positions, and positions are also emergent and diverse within a single group.

Exploration of the social interactions in administrative groups identified both action and task and role responsibilities, but there was no evidence of universal moral responsibility. It may be that while action and task and role responsibilities are more readily identified at the explicit level of social interaction, universal moral responsibility may be located at a more latent level and is therefore less easily observed. As a matter of doing good to others, ${ }^{1}$ moral responsibility can be seen as a value that is interwoven with behavior that occurs beyond other realms of responsibility. In hospitals, moral responsibility may become explicit in other group contexts - for instance, where healthcare teams make treatment decisions that prioritize the patient and their situation.

These findings suggest that, in hospital administrative groups, responsibility is constructed on many dimensions that stem from the institutional level, simultaneously creating and maintaining the institution. The institutional theory of organizational communication describes this mutual process by characterizing individuals in institutions as actors and carriers of the beliefs manifested in institutional practices, where institutions are produced and reproduced in human communication. ${ }^{10}$ Social interaction in responsibility creation therefore involves both individual participation in administrative groups and institutional norms, rules, and practices beyond these groups. The meetings can be seen as specific rituals, forming part of the fixed practices that create the institution. As part of the institution, a meeting can be described as a framework that defines participants' interaction. In a healthcare context, professional roles and their presentation can also affect communication behavior at the administrative level. In this way, the institution defines expectations and demands in relation to responsibility distribution and the involvement of administrative group members in responsibility processes. By examining how responsibility is constructed in naturally occurring interactions in hospital administrative groups, we now know more about responsibility creation in institutional settings as a relational phenomenon. The present findings indicate that in constructing responsibility, social interaction also establishes institutional features such as positioning in different roles and invokes procedures for handling that responsibility. Consequently, processes and practices such as routines for reasoning and formulating responsibility shape ways of treating and responding to responsi- bility at work. The hospital as institution is constructed and maintained through observable behaviors of this kind. Creating a shared understanding of accepted ways of engaging in or rejecting responsibility further sustains the fixed nature of institutions.

\section{Limitations}

This study approached responsibility construction from the perspective of social interaction and provided a new understanding on this focal phenomenon at many levels of hospital organizations. Despite the data's suitable size for this study's qualitative aims, more diverse data could have given a wider range of responsibility categories and types occurring in interaction.

Despite the natural setting, the researchers' presence is always likely to influence data objectivity. ${ }^{31}$ This was taken into account in the research design. As the research period was quite extended and data were collected regularly, it could be assumed that participants became accustomed to the researcher's presence, as indicated in earlier observational studies. ${ }^{44}$ When asked whether the observed meetings differed from their other meetings, participants indicated that the meetings were similar. As the data were collected as part of a larger research project, the credibility of the analysis was strengthened by discussing interpretations with members of the research group, who are familiar with the data.

\section{Conclusions}

This study contributes to knowledge about responsibility construction in the social interaction processes that form and maintain institutions, organizations, and groups. One novel and interesting implication is that, as well as responsibility, non-responsibility is created in administrative meetings. These findings can assist the development of administrative groups and their social interaction processes and practices. By understanding these interactions, it becomes possible to improve them, so enhancing the quality of group work. It is important to recognize the various dimensions of interaction in which responsibility or non-responsibility is created, and to make these processes visible by talking about them and about their meaning in the workplace. In particular, these results can be utilized in healthcare organizations, which differ from many other settings in respect of tasks, administration, organizational culture, and the multiple hierarchies, cultures, and sub-cultures that shape daily organizational life. ${ }^{3}$

These results can also be used to improve well-being at work. Given the challenges that may emerge in role and position negotiations, employees must be able to balance different responsibilities and demands. ${ }^{41}$ Ambiguous positioning may cause stress and impair well-being at work, ${ }^{42}$ and social interaction is a key element in making sense of different roles and positions as identities are ne- 
gotiated, developed, and presented through processes of communication. ${ }^{43}$ Employees' capacity to manage their different positions should be acknowledged, as clarity in this regard can strengthen group performance at many levels by supporting individual performance and enhancing satisfaction within the group. ${ }^{41}$

In relation to organizational development processes, it is also essential to consider institutional aspects, especially in contexts such as hospitals. Evaluating and developing the social interactions of individual groups may not be enough, and the institutional level should not be taken for granted as a stable and fixed construction. It is important to remember that institutions are both maintained and changed through social interaction, ${ }^{10}$ and that updating or developing practices and processes can also affect the institutional level. While administrative groups produce resources for organizations, their interaction processes can exert an influence throughout the organization.

Significantly, although nursing staff members are offered opportunities to participate in responsibility creation by joining the management group, the ways in which responsibility can be accepted or shared determine their actual potential in this regard. In other words, it is not just a simple matter of giving and taking responsibility if employees lack the capabilities or resources to deal with it. From an organizational and administrative perspective, it is important to find ways of supporting employees and their agency in responsibility creation and management. For managers, juggling responsibility sharing and being ultimately accountable can make administrative work challenging. By understanding that responsibility construction is a multifaceted process, managers can also support each other.

The present findings provide interesting insights for future research. Knowing how to support hospital employees in managing responsibility can enhance healthcare management, organization, and administration studies, as well as helping practitioners to enhance employees' agency. Further investigation of structures that promote or hamper involvement in responsibility creation is essential, along with research on the aspects of universal moral responsibility that did not emerge in this study. In healthcare organizations, which are based on the idea of helping and treating people, it would be especially useful to learn more about the role of universal moral responsibility in social interaction processes. Additionally, it would be useful to know more about the temporal aspects of responsibility, including how, when, and at what levels shared organizational truths and visions are structured, and how this affects organizational performance.

\section{References}

1. Lenk H. Responsibility for safety and risk minimization: Outline of an attribution-based approach regarding modern technological and societal systems. Hum Factor Ergon Manuf Serv Ind 2003;1:203-22.

2. Bierhoff H-W, Auhagen AE. Responsibility as a fundamental human phenomenon. In: Auhage EA, Bierhoff $\mathrm{H}-\mathrm{W}$, eds. Responsibility. The many faces of a social phenomenon. New York, NY: Routledge; 2001. pp 1-8.

3. Wright KB, Sparks L, O'Hair HD. Health communication in the 21st century. Malden, MA: Wiley-Blackwell; 2013.

4. Bowles D, McIntosh G, Hemrajani R, et al. Nurse-physician collaboration in an academic medical centre: The influence of organisational and individual factors. J Interprof Care 2016;30:655-60.

5. Opel DJ, Wilfond BS, Brownstein D, et al. Characterisation of organisational issues in paediatric clinical ethics consultation: A qualitative study. J Med Ethics 2009;35:477-82.

6. Rabøl L, McPhail MA, Østergaard D, et al. Promoters and barriers in hospital team communication. A focus group study. J Commun Healthc 2012;5:129-39.

7. Körner M, Bütof S, Müller C, et al. Interprofessional teamwork and team interventions in chronic care: A systematic review. J Interprof Care 2016;30:15-28.

8. Real K, Poole MS. Health care teams: Communication and effectiveness. In: Thompson TR, Parrot R, Nussbaum JF, eds. The Routledge handbook of health communication. 2nd ed. New York, NY: Routledge; 2011. pp 100-116.

9. von Knorring M, Alexanderson, K, Eliasson MA. Healthcare managers' construction of the manager role in relation to the medical profession. J Health Organ Manag 2016;30:421-40.

10. Lammers JC, Barbour JB. An institutional theory of organizational communication. Commun Theory 2006;16:356-77.

11. Pennanen E, Mikkola L. Work coordination as a social interaction process in nursing staff meetings. Nord J Work Life Stud 2016;6:23-41.

12. Martin JA. Dynamic managerial capabilities and the multibusiness team: The role of episodic teams in executive leadership groups. Org Sci 2011;22:118-40.

13. Woolley AW, Gerbasi ME, Chabris CF, et al. Bringing in the experts: How team composition and collaborative planning jointly shape analytic effectiveness. Small Group Res 2008;39:352-71.

14. Hoon C. Committees as strategic practice: The role of strategic conversation in a public administration. Hum Relat 2007;60:921-52.

15. Liang X, Achidi Ndofor H, Priem RL, Picken JC. Top management team communication networks, environmental uncertainty, and organizational performance: A contingency view. J Manag Issues 2010;22:436-55.

16. Lenk H, Maring M. Responsibility and technology. In: Auhage EA, Bierhoff H-W, eds. Responsibility. The many faces of a social phenomenon. New York, NY: Routledge; 2001. pp 93-108.

17. Birnbacher D. Philosophical foundations of responsibility. In: Auhage EA, Bierhoff H-W, eds. Responsibility. The many faces of a social phenomenon. New York, NY: Routledge; 2001. pp 9-22.

18. Chernev A, Blair S. Doing well by doing good: The benevolent halo of corporate social responsibility. J Consumer Res 2015;41:1412-25.

19. Villagra N, Cárdaba MA, Ruiz San Román J. Communicating corporate social responsibility: Re-assessment of classical theories about fit between CSR actions and corporate activities. Commun Society 2016;29:133-46.

20. Witt LA. Responsibility in work organisations. In: Auhage 
EA, Bierhoff H-W, eds. Responsibility. The many faces of a social phenomenon. New York, NY: Routledge; 2001. pp 139-147.

21. Lehmann-Willenbrock N, Allen JA, Kauffeld S. A sequential analysis of procedural meeting communication: How teams facilitate their meetings. J Appl Commun Res 2013;41:365-88.

22. Wilson B, Schullery N. Rotating responsibility reaps rewards. Bus Commun Q 2000;63:68-72.

23. Seibert SE, Wang G, Courtright SH. Antecedents and consequences of psychological and team empowerment in organizations: A meta-analytic review. J Appl Psychol 2011;96:981-1003.

24. Catalano K. Hand-off communication does affect patient safety. Plast Surg Nurs 2009;29:266-70.

25. Herlitz A, Munthe C, Törner M, Forsander G. The counseling, self-care, adherence approach to person-centered care and shared decision making: Moral psychology, executive autonomy, and ethics in multi-dimensional care decisions. Health Commun 2016;31:964-73.

26. Zisman-Ilani Y, Roe D, Scholl I, et al. Shared decision making during active psychiatric hospitalization: Assessment and psychometric properties. Health Commun 2017;32:126-30.

27. Brandis S, Rice J, Schleimer S. Dynamic workplace interactions for improving patient safety climate. J Health Org Manag 2017;31:38-53.

28. Burleson BR. The nature of interpersonal communication: A message-centered approach. In: Berger CR, Roloff ME, Roskos-Ewoldsen D, eds. Handbook of communication science. 2nd ed. Thousand Oaks, CA: Sage; 2010. pp 145163.

29. Sias PM. Workplace relationships. In: Putnam LL, Mumby DK, eds. The Sage handbook of organizational communication. Advances in theory, research and methods. 3rd ed. Thousand Oaks, CA: Sage; 2014. pp 375-400.

30. Silverman D. Interpreting qualitative data: A guide to the principles of qualitative research. London: Sage; 2011.

31. Angrosino M, Rosenber J. Observations on observation. Continuities and challenges. In: Denzin NK, Lincoln YS, eds. The SAGE handbook of qualitative research. Los Angeles, LA: Sage; 2011. pp 467-478.

32. Ministry of Economic Affairs and Employment. Labour legislation. Ministry of Economic Affairs and Employment;
2017. Available from: https://tem.fi/en/labour-legislation Accessed: 2017, Aug 29.

33. National Advisory Board on Research Ethics. Ethical principles of research in the humanities and social and behavioural sciences and proposals for ethical review. National Advisory Board on Research Ethics; 2009. Available from: http://www.tenk.fi/sites/tenk.fi/files/ethicalprinciples.pdf Accessed: 2017, Sep 16.

34. Braun V, Clarke V. Using thematic analysis in psychology. Qual Res Psychol 2006;3:77-101.

35. Mayan MJ. Essentials of qualitative inquiry. New York, NY: Routledge; 2009.

36. Graneheim UH, Lundman B. Qualitative content analysis in nursing research: Concepts, procedures and measures to achieve trustworthiness. Nurs Ed Today 2004;24:105-12.

37. Marková I, Linell P, Grossen M, Orvig AS. Dialogue in focus groups. Exploring socially shared knowledge. London, UK: Equinox; 2007.

38. McGlone MS, Giles H. Language and interpersonal communication. In: Knapp ML, Daly JA, eds. The Sage handbook of interpersonal communication. 4th ed. Thousand Oaks, CA: Sage; 2011. pp 201-238.

39. Montada L. Denial of responsibility. In: Auhage EA, Bierhoff H-W, eds. Responsibility. The many faces of a social phenomenon. New York, NY: Routledge; 2001. pp 79-92.

40. Harré R. Positioning theory: Moral dimensioms of socialcultural psychology. In: Valsiner J, ed. The Oxford handbook of culture and psychology. New York, NY: Oxford University Press; 2012. pp 191-206.

41. Henderson LS, Stackman RW, Lindekilde R. The centrality of communication norm alignment, role clarity, and trust in global project teams. Int J Proj Manag 2016;34:1717-30.

42. Ray EB, Apker J. Stress, burnout, and supportive communication. A review of research in health organizations. In: Thompson TR, Parrot R, Nussbaum JF. eds. The Routledge handbook of health communication. 2nd ed. New York, NY: Routledge; 2011. pp 428-440.

43. Apker J, Propp KM, Ford WS. Negotiating status and identity tensions in healthcare team interactions: An exploration of nurse role dialectics. J Appl Commun Res 2005;33:93-115.

44. Frey LR, Botan CH, Kreps GL. Investigating communication. An introduction to research methods. 2nd ed. Boston, MA: Allyn \& Bacon; 2000. 